\title{
Estimation of remaining dentine thickness below deep lesions of caries
}

\author{
P. E. Lancaster, ${ }^{1}$ H. L. Craddock ${ }^{2}$ and F. A. Carmichael ${ }^{3}$
}
IN BRIEF
- Stepwise excavation is an accepted technique for restoring deep caries lesions.
- The remaining dentine thickness influences pulp vitality and the outcome of certain restorative procedures.
- Reliable measurement of tooth dimensions from an intra-oral conventional or digital radiograph was not achievable.
- The general trend for the radiographic images was to over-estimate the remaining dentine thickness.

\begin{abstract}
Objective The objective of this study was to investigate agreement between the estimated remaining dentine thickness (RDT) under lesions of caries, measured from a conventional in vivo periapical radiograph, compared directly to the measured RDT of the tooth. Additional investigation was to be made for agreement between in vitro digital radiographs and conventional radiographs. Design and setting This was a cross-sectional, single centre study at Leeds Dental Institute, United Kingdom, in 2009. Subjects, materials and methods Twenty-five carious teeth with occlusal or proximal lesions were collected from patients aged 19 to 82 years attending the Oral Surgery Department. Each patient had a pre-extraction in vivo periapical radiograph of the tooth demonstrating an intact layer of dentine below the lesions of caries. Postextraction in vitro digital and conventional radiographs were taken. Main outcome measures Agreement of the RDT was analysed using Bland-Altman plots. Results A trend for the radiographic images to over-estimate the RDT compared to the tooth was found. Greater over-estimation of the RDT by conventional radiographs both in vivo and in vitro was shown compared to the in vitro digital images in the majority of cases. Conclusion This analysis has demonstrated it is not possible to estimate the dimension of the RDT from a periapical radiograph.
\end{abstract}

\section{INTRODUCTION}

The conventional approach to the treatment of lesions of caries is being increasingly questioned by the dental profession. The need to remove dentine in deep lesions to the point of being hard and stain-free while risking pulpal exposure if the tooth has been symptom-free is no longer necessary. ${ }^{1}$

Alternative techniques, such as atraumatic restorative treatment ${ }^{2}$ and stepwise excavation, ${ }^{3}$ appear to be very successful in maintaining pulpal health and vitality. In conventional treatment of deep lesions of caries, $40 \%$ of treated teeth had pulpal exposures compared to $17.5 \%$ with the stepwise approach. ${ }^{4}$

A number of methods have been explored to assess the remaining dentine thickness

\footnotetext{
"Department of Restorative Dentistry, ${ }^{2}$ Senior Lecturer and Honourary Consultant, Department of Fixed and Removable Prosthodontics, ${ }^{3}$ Department of Oral and Maxillofacial Radiology, Leeds Dental Institute, University of Leeds, Worsley Building, Clarendon Way, Leeds, LS2 9LU

*Correspondence to: Miss Paula E. Lancaster Email: p.e.lancaster@leeds.ac.uk
}

Online article number E20

Refereed Paper - accepted 4 March 2011

DOI: 10.1038/sj.bdj.2011.965

${ }^{\circledR}$ British Dental Journal 2011; 211: E20 beneath lesions of caries. These include electrical resistance ${ }^{5}$ and the Prepometer. ${ }^{6}$ However, the radiograph is the most readily available method to the dental practitioner. It is important to understand how reliable intra-oral radiography is for the estimation of any tooth dimension and it is commonly accepted that radiographs underestimate the depth of carious lesions by as much as $1 \mathrm{~mm} .^{7}$

The depth of remaining dentine may give an indication of likely pulp vitality. ${ }^{8}$ If it were possible to accurately measure the depth of the remaining dentine thickness and, therefore, the proximity of the pulp to the base of a lesion, excavation could be terminated before exposing the pulp.

The amount of remaining dentine thickness can influence treatment outcomes:

- $1 \mathrm{~mm}$ of residual root dentine ${ }^{9}$ following post preparation is claimed to reduce the risk of root fracture

- Pulpal toxicity of certain materials (eg zinc oxide eugenol ${ }^{10}$ ) reduces with increasing dentine thickness

- Bond strength of resin-based adhesive systems reduces as the dentine thickness reduces. ${ }^{11}$ Resin-modified glass-ionomer adhesive is similarly affected ${ }^{12}$
- Hydraulic conductance of radicular dentine decreases with increasing distance from the pulp ${ }^{13}$

- Heat-induced pulpal injury following curing $^{14}$ of composite material with light-emitting diode units or from burs during caries removal is more likely with reduced dentine thickness.

Pulp vitality is influenced by the remaining dentine thickness. ${ }^{8,15}$ The number of odontoblasts reduces as the remaining dentine thickness reduces. Severe pulpal inflammation appears to be influenced by the remaining dentine thickness, ${ }^{16}$ allowing the effects of bacteria to reach the pulp more readily when reduced. Previous studies have suggested a remaining dentine thickness of $2 \mathrm{~mm}$ for protection of the pulp, ${ }^{17}$ others suggest $1 \mathrm{~mm}^{18}$ but a minimum of $0.5 \mathrm{~mm}$ is now accepted. ${ }^{8}$ When the lesion reaches within $0.25 \mathrm{~mm}-0.3 \mathrm{~mm}$ of the pulp, inflammatory reactions of pulpitis and hyperaemia are initiated. ${ }^{19}$

The greatest deposits of reactionary dentine occur with a remaining dentine thickness of $0.25 \mathrm{~mm}-0.5 \mathrm{~mm}$ and the presence of bacteria can exacerbate this. ${ }^{15}$ A remaining dentine thickness of less than 
$0.25 \mathrm{~mm}$ can injure the odontoblasts, hindering their secretion abilities. At $0.5 \mathrm{~mm}$ and below, odontoblast numbers are reduced by $33.7 \%$, whereas a reduction of $13.6 \%$ is observed at a thickness of $0.25 \mathrm{~mm}-0.5 \mathrm{~mm}^{8}$

The success rate of stepwise excavation after $36-45$ months is $88 \% .{ }^{20}$ Direct pulpcapping has a success rate of $37 \%$ at five years and a failure rate of $80 \%$ after ten years, following a carious exposure. ${ }^{21}$

The aim of this project was to ascertain if it was possible to conveniently measure the depth of remaining dentine thickness under lesions of caries from a radiograph, by demonstrating agreement between measurements taken from a radiograph and excavation of the tooth.

Digital images are increasing in popularity and an in vitro digital image and conventional radiograph were compared to the tooth measurements to assess agreement of remaining dentine thickness.

\section{METHOD}

This was a cross-sectional, single-centre study at Leeds Dental Institute, United Kingdom, in 2009. Ethical approval was gained from Leeds West Ethics Committee for collection of 25 teeth with corresponding in vivo radiographs.

Adult patients aged 19-82 years, attending Leeds Dental Institute for the removal of a posterior tooth (ie a premolar or molar) who had an accompanying periapical (PA) radiograph (Fig. 1a) demonstrating remaining dentine beneath a lesion of caries, were invited to take part. Written, informed consent was obtained from all subjects following a verbal explanation about the purpose of the study and the methods to be used. An explanatory leaflet was provided for each patient.

Each tooth collected was placed in a $20 \mathrm{ml}$ plastic vial (Sterilin UK) with ice.

In vivo periapical films (Kodak Insight, F-speed, Size 2, Claudius Ash, Potters Bar, Herts, UK) were taken in the course of normal treatment, before removal of the tooth. Rinn Film Holders (Claudius Ash, Potters Bar, Herts, UK) were used with a Focus Intra X-ray Unit (7 ma, $0.25 \mathrm{sec}, 70 \mathrm{Kv}$, posterior setting, focal spot to skin surface distance 320 mm, GE Health Care Dental, Tuusula, Finland) and were developed with a Velopex Automatic Processor (Velopex, Harlseden, London, UK).

\begin{tabular}{|c|c|c|c|c|c|c|c|c|c|c|}
\hline \multirow[t]{2}{*}{ Tooth } & \multirow[t]{2}{*}{$\begin{array}{l}\text { Arch/ } \\
\text { Lesion }\end{array}$} & \multirow[t]{2}{*}{$\begin{array}{l}\text { Gender/ } \\
\text { Age(yrs) }\end{array}$} & \multicolumn{2}{|c|}{$\begin{array}{l}\text { In vitro } \\
\text { tooth RDT } \\
(\mathrm{mm})\end{array}$} & \multicolumn{2}{|c|}{$\begin{array}{l}\text { In vivo } \\
\text { radiograph } \\
\text { RDT (mm) }\end{array}$} & \multicolumn{2}{|c|}{$\begin{array}{l}\text { In vitro } \\
\text { radiograph } \\
\text { RDT (mm) }\end{array}$} & \multicolumn{2}{|c|}{$\begin{array}{l}\text { In vitro } \\
\text { Digora RDT } \\
(\mathrm{mm})\end{array}$} \\
\hline & & & & IA & & IA & & IA & & IA \\
\hline 1 & Max/P & $M / 33$ & \multicolumn{2}{|l|}{0.5} & \multicolumn{2}{|l|}{1.0} & \multicolumn{2}{|l|}{1.5} & \multicolumn{2}{|l|}{1.0} \\
\hline 2 & Man/0 & $M / 34$ & \multicolumn{2}{|l|}{2.0} & \multicolumn{2}{|l|}{2.0} & \multicolumn{2}{|l|}{2.0} & \multicolumn{2}{|l|}{2.0} \\
\hline 3 & Man/P & $M / 22$ & \multicolumn{2}{|l|}{2.5} & \multicolumn{2}{|l|}{3.0} & \multicolumn{2}{|l|}{2.5} & \multicolumn{2}{|l|}{3.0} \\
\hline 4 & Max/0 & $F / 22$ & \multicolumn{2}{|l|}{0.5} & \multicolumn{2}{|l|}{1.5} & \multicolumn{2}{|l|}{1.0} & \multicolumn{2}{|l|}{1.0} \\
\hline 5 & $\operatorname{Max} / \mathrm{P}$ & $M / 29$ & 1.0 & 1.0 & 2.0 & 2.0 & 2.0 & 1.5 & 1.5 & 1.5 \\
\hline 6 & Man/P & $\mathrm{M} / 77$ & \multicolumn{2}{|l|}{1.0} & \multicolumn{2}{|l|}{2.0} & \multicolumn{2}{|l|}{2.0} & \multicolumn{2}{|l|}{1.0} \\
\hline 7 & Man/0 & $\mathrm{M} / 40$ & \multicolumn{2}{|l|}{1.0} & \multicolumn{2}{|l|}{2.0} & \multicolumn{2}{|l|}{2.0} & 2.0 & \\
\hline 8 & $\operatorname{Max} / \mathrm{P}$ & $\mathrm{M} / 81$ & 0.5 & & 1.0 & & 1.0 & & 1.0 & \\
\hline 9 & Man/0 & $F / 35$ & 1.0 & & 1.0 & & 0.5 & & 0.5 & \\
\hline 10 & Man/P & $\mathrm{F} / 53$ & 1.0 & 1.0 & 2.0 & 2.0 & 2.0 & 2.0 & 1.5 & 2.0 \\
\hline 11 & $\operatorname{Max} / \mathrm{P}$ & $\mathrm{M} / 27$ & 1.0 & & 2.0 & & 3.0 & & 2.0 & \\
\hline 12 & Man/P & $\mathrm{M} / 30$ & 1.0 & & 1.5 & & 0.5 & & 1.0 & \\
\hline 13 & Man/0 & $\mathrm{M} / 76$ & 3.5 & & 3.5 & & 3.0 & & 3.0 & \\
\hline 14 & $\operatorname{Max} / 0$ & $\mathrm{M} / 47$ & 1.0 & & 3.0 & & 3.0 & & 3.0 & \\
\hline 15 & Man/P & $\mathrm{M} / 28$ & 0.5 & & 0.5 & & 1.5 & & 1.0 & \\
\hline 16 & $\operatorname{Max} / \mathrm{P}$ & $\mathrm{F} / 41$ & 0.5 & 0.5 & 0.5 & 0.5 & 1.0 & 1.0 & 1.0 & 1.0 \\
\hline 17 & $\operatorname{Max} / \mathrm{P}$ & $\mathrm{M} / 41$ & 1.0 & & 2.0 & & 1.0 & & 1.0 & \\
\hline 18 & $\operatorname{Max} / \mathrm{P}$ & $M / 35$ & 2.5 & & 3.0 & & 2.0 & & 1.5 & \\
\hline 19 & $\operatorname{Max} / \mathrm{P}$ & $F / 19$ & 3.0 & & 3.0 & & 3.0 & & 3.0 & \\
\hline 20 & Man/P & $\mathrm{M} / 48$ & 1.0 & 1.0 & 2.0 & 2.5 & 2.0 & 2.0 & 2.0 & 2.0 \\
\hline 21 & $\operatorname{Max} / \mathrm{P}$ & $M / 65$ & 2.0 & & 2.5 & & 1.5 & & 1.5 & \\
\hline 22 & $\operatorname{Max} / \mathrm{P}$ & $F / 29$ & 1.5 & & 1.5 & & 1.0 & & 1.0 & \\
\hline 23 & Man/P & $F / 29$ & 0.5 & & 1.0 & & 1.0 & & 1.5 & \\
\hline 24 & $\operatorname{Max} / \mathrm{P}$ & $\mathrm{M} / 37$ & 1.0 & & 1.5 & & 2.0 & & 1.5 & \\
\hline 25 & $\operatorname{Max} / \mathrm{P}$ & $\mathrm{F} / 30$ & 1.0 & 1.0 & 2.0 & 2.0 & 1.0 & 1.0 & 1.0 & 2.0 \\
\hline
\end{tabular}

The in vitro radiograph was taken with the tooth placed directly on a radiographic film (Kodak Insight, F-speed, Size 2, Claudius Ash, Potters Bar, Herts, UK) with the Prostyle Intra Machine (Planmeca, $70 \mathrm{Kv}$, focal spot to skin surface distance 315 mm, Claudius Ash, Potters Bar, Herts, UK) set to the recommended anatomical exposures. The radiographic cone was placed in a lead-lined box at the same depth for each film. The Kodak films were processed with the Velopex Automatic Processor. The remaining dentine thickness was measured on the periapical radiograph in a darkened room, on a viewing box, with a viewing area the size of the film cut out of black card. No magnification was used.

The digital image (Fig. 1c) was taken on Digora Optime Imaging Plates (Size 2, Soredex, Tuusula, Finland) in the same way as the in vitro radiograph. The Digora Plates were processed with the Digora Optime (Soredex, Tuusula, Finland). This was linked to a Dell Computer and Screen and used the programme Digora for Windows 2.5 Rev 1, Soredex, 1993-2005. The screen size was 17 inches, 
with $1,024 \times 768$ pixels, 32 bit colour-depth and 96 dpi resolution. The programme allowed direct digital measurement of the required dimensions.

The tooth was sectioned in the mesiodistal plane within the hour. A silicone rubber-headed $50 \mathrm{~mm}$ hand-clamp (BEtQ, Leeds, UK) held the tooth for sectioning and was attached with G-clamps (BetQ, Leeds, UK) to a laminated wooden frame secured with G-clamps (BCtQ, Leeds, UK) to a phantom-head.

The diamond cutting disc (Skillbond, High Wycombe, UK, Sintered Diamond Disc, size 400, 1/10 mm set 638R1) was used in a Kavo EWL K9 hand-piece (Kavo Dental Ltd, Amersham, Bucks, UK). This was replaced after every fifth section. Water from the 3-in-1 syringe was used as a coolant.

The portion of the tooth with visually the deepest lesion was hand-excavated, using small and medium excavators (Henry Schein, Kent, UK) to the point of clinical acceptance of remaining dentine, ie the dentine was firm to the application of moderate excavation force. The remaining dentine thickness following hand-excavation (Fig. 1d) was measured directly on the tooth using a clear plastic ruler. ${ }^{22}$ Measurements were taken from the thinnest point of remaining dentine on the floor of the lesion to the pulp dentine border $^{8}$ to the nearest $0.5 \mathrm{~mm}$.

Thus, a total of four measurements were taken:

- In vivo conventional PA

- In vitro conventional PA

- In vitro Digora digital image

- Post hand-excavation.

Repeat measurements to assess intraoperator agreement were made on $20 \%$ of the samples selected at random (Table 1).

\section{Statistical analysis}

Statistical analysis was by graphical technique using Bland-Altman plots to demonstrate agreement of the continuous variables. ${ }^{23}$ This utilises the difference between two measurements and their mean. The mean of the differences is shown as the bias line and the standard deviation (SD) of the differences demonstrates the 95\% limits of agreement. This was carried out using SPSS 14

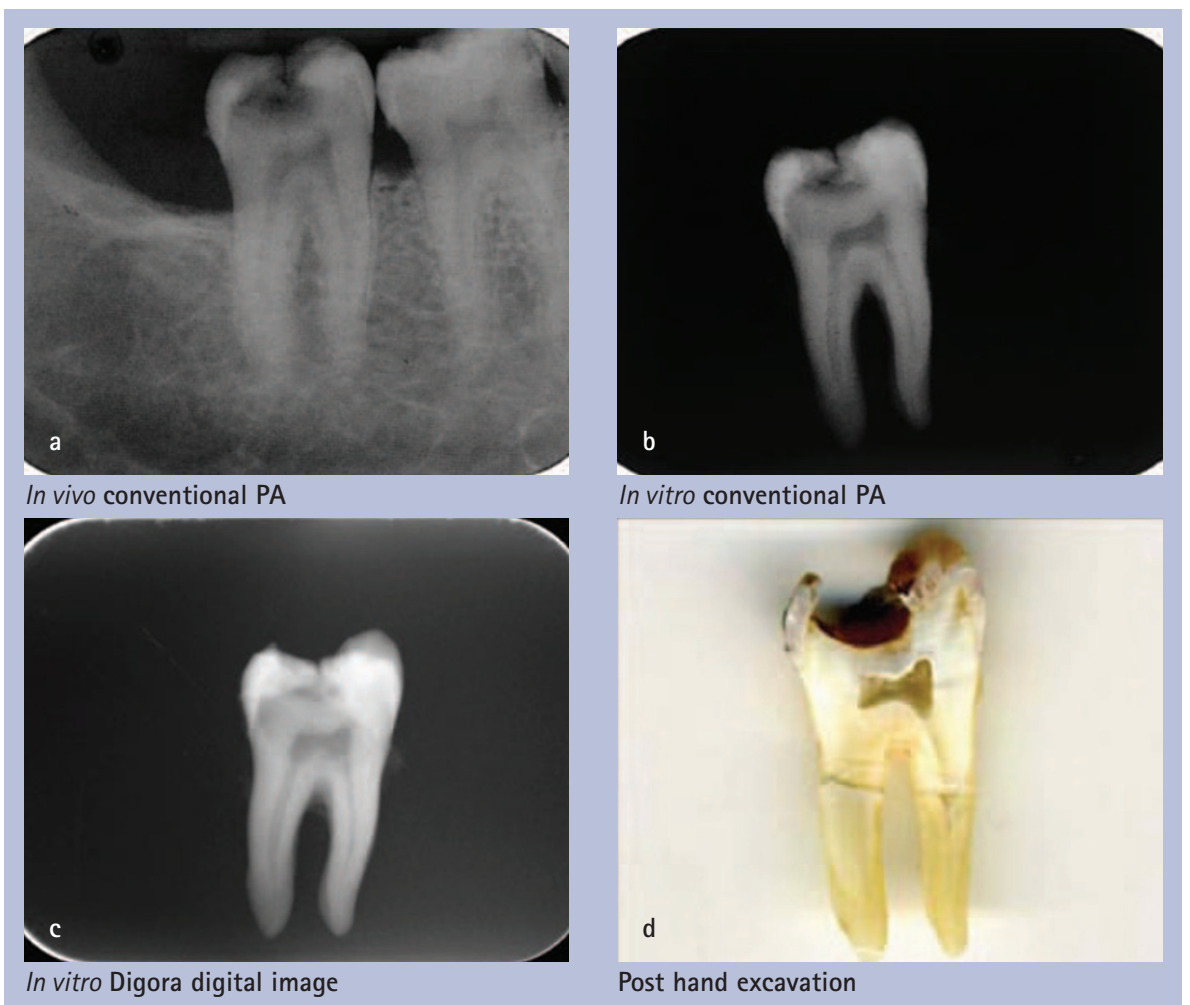

Fig. 1 A sample of each image taken

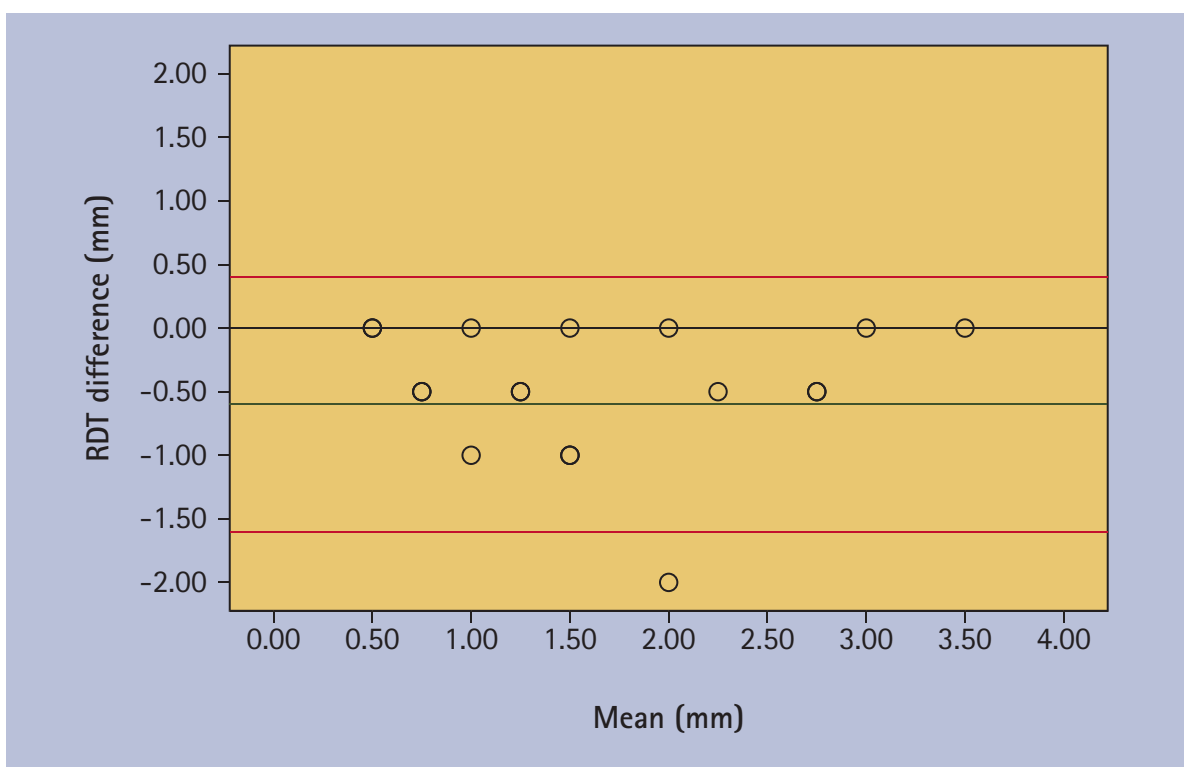

Fig. 2 Bland-Altman plot of remaining dentine thickness of in vitro tooth and in vivo radiograph

\section{RESULTS}

\section{Subject data}

This study consisted of 17 males and 8 females aged between 19 and 82 years, with a mean age of 40.3 years, SD 17.5.

The Bland-Altman plot of remaining dentine thickness of the in vitro tooth and the in vivo radiograph (Fig. 2) demonstrates agreement does occur in over a quarter of cases (7/25) and the in vivo periapical value is always equal to, or greater than, the tooth value, indicating a trend for the radiograph to over-estimate the RDT.

Figure 3 demonstrates the agreement between in vitro tooth and in vitro periapical radiograph, where there is agreement in a fifth of the sample (5/25) and there is over- and under-estimation of the dimensions radiographically.

Figure 4 represents the agreement between the in vitro tooth and in vitro Digora digital image, where there is agreement for just under a quarter of the sample (6/25). As with the conventional radiographs, the majority of samples 
(20/25) digitally equal or over-estimate the dimensions.

Very good agreement between the in vivo and in vitro radiographs was demonstrated with a bias line of $0.16 \mathrm{~mm}$, and between the in vitro radiograph and digital image at $0.14 \mathrm{~mm}$.

\section{DISCUSSION}

Measurements of the teeth and the radiographs were taken by means of a clear plastic ruler. This method has been used in other studies for measuring tooth dimensions, for example enamel. ${ }^{22}$ It may be argued that this may magnify the measurements but this will be the case for all measurements. This basic method of measurement was chosen as it can be replicated easily in an unmodified practice setting. It is a simple, fast and readily available method carried out at the chair-side.

The decision to measure to the nearest $0.5 \mathrm{~mm}$ was based on the premise that this is the minimum depth of remaining dentine acceptable before there is evidence of pulpal injury. ${ }^{8}$

The actual measurements taken were from the thinnest point of remaining dentine on the floor of the lesion and the pulp dentine border. ${ }^{8}$ This proved very difficult at times due to the variation of mineral dissolution of the margins of the carious lesion. There will, inevitably, be an element of human error in the transfer from one image to another in maintaining the identical point to be measured compared to the tooth.

All measurements were taken by one examiner. The accessibility to two examiners for the measurements of the actual tooth was, unfortunately, logistically impossible within the hour of collection. As agreement was being investigated between the tooth and the radiographs, having only one examiner for the tooth measurements and two for the radiographs, would not have added to the validity of the results. Observer variability is a major factor in diagnostic performance and is rarely controllable. ${ }^{24}$ Intra-examiner agreement measurements were taken for $20 \%$ of the samples to determine examiner reliability, which was good.

The radiographic and digital images of the teeth were taken, stored and read at a separate time to the measurements of the teeth. The radiographs were read in

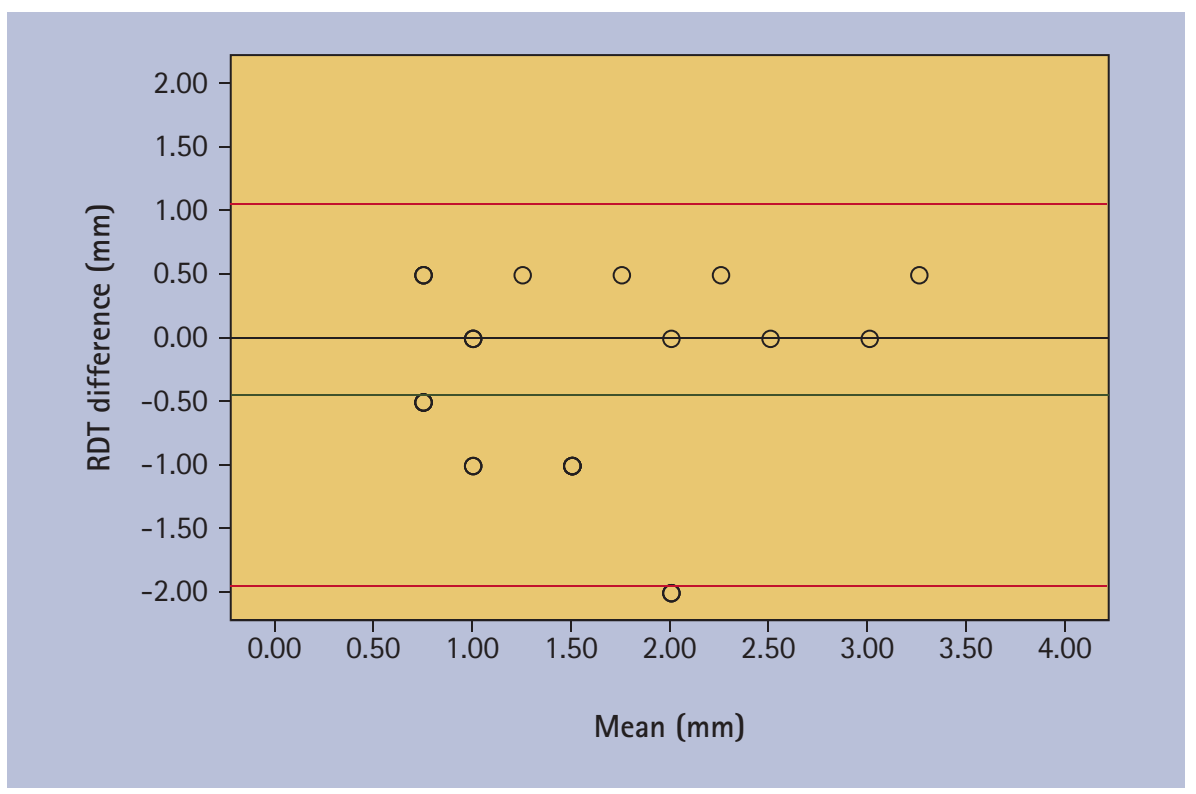

Fig. 3 Bland-Altman plot of remaining dentine thickness of in vitro tooth and in vitro radiograph

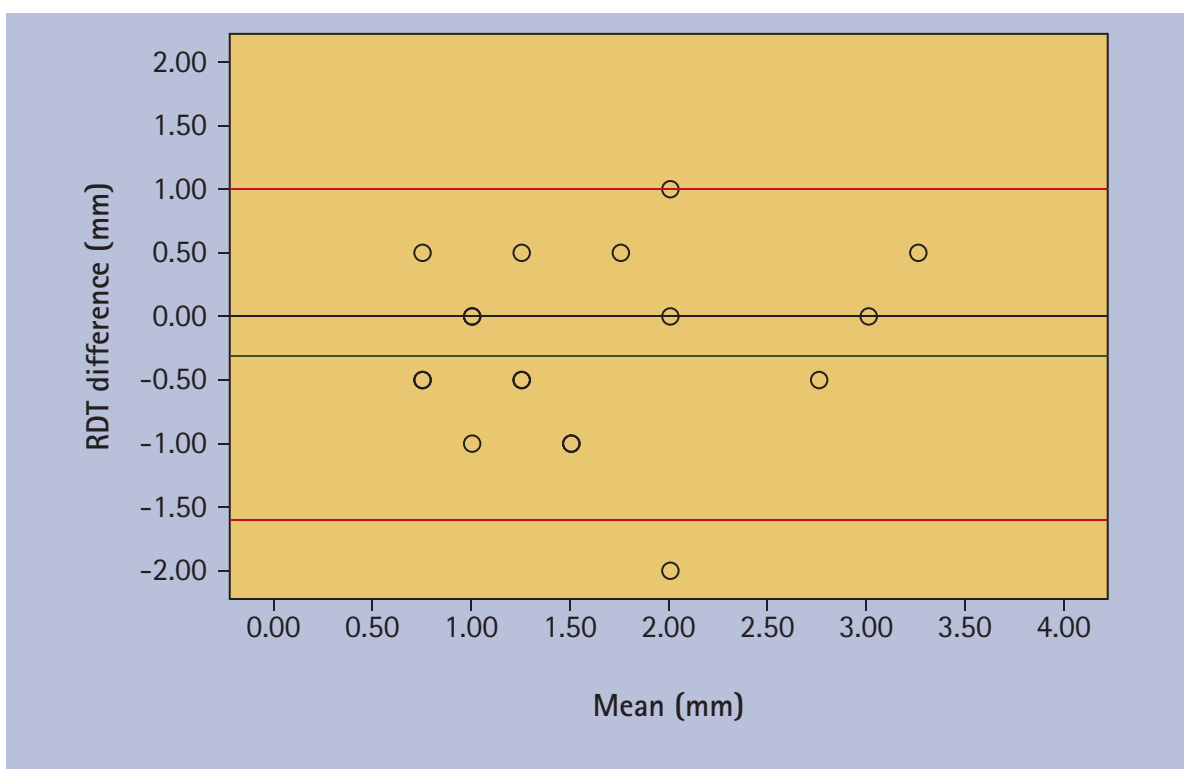

Fig. 4 Bland-Altman plot of remaining dentine thickness of in vitro tooth and in vitro Digora image

a quiet, darkened room on a viewer. ${ }^{25}$ No magnification was used.

All studies have limitations and the ideal radiograph for caries detection is the bitewing ${ }^{26}$ but it was not clinically justifiable to take a bitewing radiograph for this study. The peri-apical images were taken using film holders, and the projection geometry in relation to the crown of the tooth and the magnification is likely to be similar to a bitewing image.

The in vitro images may be made more consistent by the use of a device to hold the teeth and film in a standardised position $^{27}$ and to attempt to replicate the soft tissues $^{28}$ by the use of plasticine or a similar material. Svanæs et al..$^{29}$ utilised a method of simultaneous exposure for the digital and conventional image receptors to obtain geometric accuracy.

All images will be susceptible to magnification and some level of distortion as perfect geometry is unlikely. This is reduced by the use of film holders intra-orally to allow comparison with similar intra-oral films. However, in reality even this clinical application will not be totally reproducible, but it does minimise the level of distortion and magnification between images. The positioning of the teeth directly on the films in vitro is unlikely to replicate the film positioning in vivo perfectly but the results in this case demonstrated very good agreement between the in vivo and in vitro 
radiographs (bias line $0.16 \mathrm{~mm}$ ). Very good replication between the in vitro images was also demonstrated (bias line $0.14 \mathrm{~mm}$ ). The dilemma continues as to how to consistently reduce such discrepancies clinically.

\section{CONCLUSIONS}

From the above analysis, the following conclusions may be drawn:

1. It is not possible to accurately determine the dimension of the remaining dentine thickness from a periapical radiograph

2. The in vivo radiographs over-estimate the amount of remaining dentine thickness under lesions of caries in the majority of cases. No underestimation was found

3. The Digora Optime digital image generally over-estimates the remaining dentine thickness

4. The in vivo and in vitro radiographs generally over-estimate the remaining dentine thickness by a greater degree than the Digora Optime digital image.

1. Kidd E A M. How 'clean' must a cavity be before restoration? Caries Res 2004; 38: 305-313.

2. Massara M L A, Alves J B, Brandão P R G. Atraumatic restorative treatment: clinical ultrastructural and chemical analysis. Caries Res 2002; 36: 430-436.

3. Bodecker C F. Histological evidence of the benefits of temporary fillings and successful pulp capping of deciduous teeth. J Am Dent Assoc 1938; 25: 777-786.

4. Leksell E, Ridell K, Cvek M, Mejare I. Pulp exposure after stepwise versus direct complete excavation of deep carious lesions in young posterior permanent teeth. Endod Dent Traumatol 1996; 12: 192-196.

5. Yoshida H, Tsuji M, Matsumoto H. An electrical method for examining remaining dentine thickness. J Dent 1989; 17: 284-286.

6. Purton D G, Chandler N P, Monteith B D, Qualtrough A J. A novel instrument to determine pulp proximity. Eur J Prosthodont Restor Dent 2009; 17: 30-34.

7. Ricketts D, Kidd E, Smith B, Wilson R. Radiographic detection of occlusal caries: effect of $X$-ray beam factors on diagnosis. Eur J Prosthodont Restor Dent 1994; 2: 149-154.

8. Murray P E, Smith A J, Windsor L J, Mjör I A Remaining dentine thickness and human pulp responses. Int Endod J 2003; 36: 33-43.

9. Caputo A A, Standlee J P. Pins and posts - why when and how. Dent Clin North Am 1976; 20: 299-311.

10. Galler K, Hiller K-A, Ettl T, Schmalz G. Selective influence of dentine thickness upon cytotoxicity of dentine contacting materials. J Endod 2005; 31: 396-399.

11. McCabe J F, Rusby S. Dentine bonding agents - characteristic bond strength as a function of dentine depth J Dent 1992 : 20: 225-230.

12. Inoue $S$, Van Meerbeek $B, A$ be $Y$ et al. Effect of remaining dentine thickness and the use of conditioner on micro-tensile bond strength of a glass ionomer adhesive. Dent Mater 2001: 17: 445-455.

13. Fogel H M, Marshall F J, Pashley D H. Effects of distance from the pulp and thickness on the hydraulic conductance of human radicular dentine. J Dent Res 1988; 67: 1381-1385.

14. Durey K, Santini A, Miletic V. Pulp chamber temperature rise during curing of resin-based composites with different light-curing units. Prim Dent Care 2008; 15: 33-38.

15. Murray P E, Lumley P J, Smith A J. Preserving the vital pulp in operative dentistry: 3 . Thickness of remaining cavity dentine as a key mediator of pulpal injury and repair responses. Dent Update 2002; 29: 172-178.

16. Hebling J, Giro E M A, Costa C A S. Human pulp response after an adhesive system application in deep cavities. J Dent 1999; 27: 557-564.

17. Stanley H R. Dental iatrogenesis. Int Dent J 1994, 44: 3-18

18. Pameijer $\mathrm{C} H$, Stanley H R, Ecker G. Biocompatibility of a glass ionomer luting agent. Part II: crown cementation. Am J Dent 1991: 4: 134-141.

19. Shovleton D S. A study of deep carious dentine. Int Dent J 1968; 18: 392-405.

20. Maltz M, Oliveira E F, Fontanella V, Carminatti G Deep caries lesions after incomplete dentine caries removal: 40-month follow-up study. Caries Res 2007; 41: 493-496.

21. Ricketts $D$. Management of the deep carious lesion and the vital pulp dentine complex. Br Dent J 2001; 191: 606-610.

22. Alvesalo L, Tammisalo E. Enamel thickness in $45, X$ females' permanent teeth. Am J Hum Genet 1981; 33: 464-469.

23. Bland J M, Altman D G. Statistical methods for assessing agreement between two methods of clinical measurement. Lancet 1986; 1(8476): 307-310.

24. Khan E A, Tyndall D A, Caplan D. Extra-oral imaging for proximal caries detection: bitewings vs scanogram. Oral Surg Oral Med Oral Pathol Oral Radiol Endod 2004; 98: 730-737.

25. Carmichael F. The consistent image - how to improve the quality of dental radiographs: 2 . The image receptor, processor and darkroom/filmhandling. Dent Update 2006; 33: 39-42.

26. Kidd E A M, Pitts N B. A reappraisal of the value of the bitewing radiograph in the diagnosis of posterior caries. Br Dent J 1990; 169: 195-200.

27. Souza E M, Bretas R T, Cenci M S, Maia-Filho E M Bonetti-Filho I. Periapical radiographs over-estimate root canal wall thickness during post space preparation. Int Endod J 2008; 41: 658-663.

28. Naoum H J, Chandler N P, Love R M. Conventional versus storage phosphor-plate digital images to visualize the root canal system contrasted with a radiopaque medium. J Endod 2003; 29: 349-352.

29. Svanæs D B, Møystad A, Larheim T A. Approximal caries depth assessment with storage phosphor versus film radiography. Caries Res 2000; 34: 448-453. 